\title{
Plasmacytoid Dendritic Cells Control Lung Inflammation and Monocyte Recruitment in Indirect Acute Lung Injury in Mice
}

\author{
Fabienne Venet, Xin Huang, Chun-Shiang Chung, \\ Yaping Chen, and Alfred Ayala \\ From the Division of Surgical Research, Rhode Island Hospital \\ Brown University, Providence, Rhode Island
}

Indirect acute lung injury (ALI, not caused by a direct insult to the lung) represents the first organ dysfunction in trauma patients, with nonpulmonary sepsis being the most common cause of indirect ALI. Dendritic cells (DCs) are thought to participate in a number of inflammatory lung diseases; however, their role in indirect ALI is currently not established. Using a clinically relevant model of indirect ALI induced in mice by hemorrhagic shock followed 24 hours later by polymicrobial septic challenge, we report that mature DC numbers were markedly increased in the lung during indirect ALI. DC depletion induced a significant increase in indirect ALI severity, which was associated with enhanced lung and plasma proinflammatory cytokine concentration and recruitment of proinflammatory $\mathrm{CD} \mathrm{S}^{+}$monocytes in response to increased lung monocyte chemotactic protein-1 production. Among the different DC subpopulations, plasmacytoid DCs, which were induced and activated in the lung during indirect ALI, were responsible for this effect because their specific depletion reproduced the observations made in DC-depleted mice. As the recruitment of monocytes to the lung plays a central deleterious role in the pathophysiology of indirect ALI, our data therefore position plasmacytoid DCs as important regulators of acute lung inflammation. (Am J Pathol 2010, 176:764-773; DOI: 10.2353/ajpath.2010.090765)

Acute lung injury (ALI) and its most severe form, the acute respiratory distress syndrome (ARDS), are the two parts of a clinical syndrome defined by acute hypoxemic respiratory failure, bilateral pulmonary infiltrate attributable to edema, and normal cardiac filling pressures. ${ }^{1}$

Of those seriously injured trauma victims who survive the first hours immediately after injury, upwards of $50 \%$ develop some forms of multiple organ failure. In this respect, $A L I$ is reported to be one of the most common forms of organ dysfunction in these individuals. ${ }^{1-2}$ Every year, ALI and ARDS are thus the cause of more than 74,000 deaths in the United States. ${ }^{2}$

This syndrome can be categorized into direct (pulmonary) and indirect (nonpulmonary) ALI. Epidemiologically, direct ALI accounts for $57 \%$ of all cases and is caused mainly by pneumonia, aspiration, and lung trauma. Indirect ALI accounts for the residual 43\% with nonpulmonary sepsis being the most frequent underlying disease. ${ }^{3}$ Among all causes, sepsis is associated with the highest risk of progression to ALI (approximately $40 \%$ ) and sepsis-associated ARDS carries the highest mortality rates from ARDS. ${ }^{1,2,4}$ Importantly, patients developing $\mathrm{ALI}$ after nonpulmonary sepsis (indirect $\mathrm{ALI}$ ) present with a higher mortality rate than patients with pulmonary sepsis (direct ALI). ${ }^{5}$

Despite almost 35 years of intense investigation, the fundamental mechanisms that initiate and propagate lung injury have not yet been defined completely. ${ }^{1}$ In particular, mechanisms leading to direct versus indirect ALI may be different, with pulmonary infections causing lung injury directly via the pathogen and host response versus nonpulmonary infections causing lung injury indirectly via systemic inflammation. ${ }^{1}$ Moreover, findings from a number of studies suggest that "priming" of different cell types occurs and appears to play significant roles in mediating the increased inflammation associated with this injury. ${ }^{1,6}$ However, despite a good understanding of the process that initiates and promotes host inflammation, little is known about the host immune cells that are responsible for the inhibition of the inflammatory response.

Supported by NIH grant R01 HL73525 (to A.A.). Purchase and operation of FACSAria was supported by NCCR SIG grant \#1S10RR021051-01A2.

Accepted for publication October 7, 2009.

Supplemental material for this article can be found on http://ajp. amjpathol.org

Address reprint requests to Alfred Ayala, Ph.D., Division of Surgical Research, Rhode Island Hospital, 593 Eddy Street, Providence, RI 02903. E-mail: AAyala@Lifespan.org 
Dendritic cells (DCs), both myeloid (mDCs) and plasmacytoid (pDCs), exist in the lung in relatively small numbers. ${ }^{7,8}$ In this location, they are ideally positioned to play a central role in the immune response during infection/inflammation. ${ }^{7,8}$ Indeed, a role for DCs has been shown in a number of lung inflammatory diseases in human (asthma, chronic obstructive pulmonary disease, lung cancer, or transplant rejection). ${ }^{7}$ Moreover, during ongoing inflammation, DCs migrate to the lung where they not only maintain and enhance local immune response, but also regulate this response. ${ }^{7,9}$ Therefore, we hypothesized that DCs have a role in the pathophysiology of indirect ALI. We investigated this using a clinically relevant model of indirect ALI induced in mice by a hemorrhagic shock followed 24 hours later by a polymicrobial septic challenge.

\section{Materials and Methods}

\section{Animals}

Male transgenic CD11C-DTR (Diphtheria Toxin Receptor) mice (B6.FVB-Tg[Itgax-DTR/EGFP]57Lan/J) 8 to 10 weeks old were used in comparison with age-matched control mice (C57BL/6; Jackson Laboratory, Bar Harbor, $\mathrm{ME})$. Experiments were done in accordance with $\mathrm{Na}$ tional Institute of Health (Bethesda, MD) guidelines and were approved by Rhode Island hospital's animal use committee.

\section{Indirect $A L I$}

Indirect ALI was induced by hemorrhagic shock (Hem) followed by cecal ligation and puncture (CLP) 24 hours later as previously described in our laboratory. ${ }^{10-13}$

\section{Hemorrhage}

In brief, mice were anesthetized with isoflurane, restrained in a supine position, and catheters were inserted into both femoral arteries (all incisions bathed in lidocaine during this protocol). Anesthesia was discontinued and blood pressure was continuously monitored through one catheter attached to a blood pressure analyzer (BPA; MicroMed, Louisville, KY). When fully awake, as determined by a mean blood pressure of $\approx 95 \mathrm{~mm} \mathrm{Hg}$, the mice were bled over a five- to ten-minute period to a mean blood pressure of $30 \pm 5 \mathrm{~mm} \mathrm{Hg}$ and were kept stable for 90 minutes. Immediately after hemorrhage, mice were resuscitated with Ringer's lactate at four times the drawn blood volume. After resuscitation, arteries were ligated, catheters were removed, catheter sites were sutured, and mice were returned to their cages. Sham hemorrhage was performed as control, and these mice underwent the same surgical procedure. However, no blood was withdrawn.

\section{Polymicrobial Sepsis}

To summarize, mice were anesthetized with isoflurane and were restrained in supine position. A 1-cm midline incision was made and the cecum was ligated with 5-0 silk threads and punctured twice with a 22-gauge needle. The cecum was then replaced, the incision was sutured, and lidocaine was applied. Mice were resuscitated with 1 $\mathrm{ml}$ of Ringer's lactate (s.c.) and returned to their cages.

\section{Intraperitoneal Injection of Diphtheria Toxin}

Intraperitoneal (i.p.) injections of diphtheria toxin (DTx, 4 $\mu \mathrm{g} / \mathrm{kg}$ ) in CD11C-DTR and in C57BL/6 mice were performed 12 hours before the induction of indirect acute lung injury. The ablation of DCs was monitored 24 hours after CLP by the measurement of the percentage of $\mathrm{CD} 11 \mathrm{C}^{+} \mathrm{MHC} \mathrm{I}^{+}$cells both in lung and in spleen by flow cytometry. ${ }^{14}$

\section{Intratracheal Instillation of Diphtheria Toxin, Clodronate Liposomes, or Antibodies}

Intratracheal (i.t.) instillations of DTx $(2 \mu \mathrm{g} / \mathrm{kg})$ in CD11cDTR and in C57BL/6 mice, of functional grade purified anti-mPDCA-1 (Plasmacytoid Dendritic Cell Antigen-1) antibody (100 $\mu \mathrm{g} / \mathrm{mice}$ - clone JF05-1C2.4.1 - Miltenyi Biotec, Auburn, CA), or anti-monocyte chemotactic protein-1 (MCP-1) neutralizing antibody (75 $\mu \mathrm{g} / \mathrm{mice}$ - clone 123616 - R\&D Systems, Minneapolis, MN) or corresponding $\operatorname{lgG}_{2 b}$ (R\&D Systems) were performed as previously described. ${ }^{10}$ Briefly, mice were lightly anesthetized using isoflurane and placed vertically, their tongues were pulled out, and using a long-nasal tip liquid was placed at top of the trachea and actively aspirated by the mouse. Gasping of treated mice verified liquid application to the alveolar space. Similarly, clodronate $\left(\mathrm{Cl}_{2} \mathrm{MBP}\right)$ and control (PBS) liposomes (100 $\mu \mathrm{l} / \mathrm{mouse})$, which were generously provided by Dr. van Rooijen (Department of Molecular Cell Biology, Amsterdam, NL), were injected i.t. into the mouse lungs 12 hours before induction of indirect ALI. ${ }^{15}$

\section{Experimental Groups and Sample Acquisition}

Twenty-four hours after CLP, mice were euthanized with an overdose of $\mathrm{CO}_{2}$. Blood was collected via cardiac puncture into heparinized syringes. Blood samples were centrifuged, and plasma was collected and stored at $-80^{\circ} \mathrm{C}$ for cytokine analysis. The left lobe of the lung was ligated and harvested for histology. Bronchoalveolar lavage fluid (BALF) was then collected to assess protein concentration as an index of lung permeability (injury). The trachea was exposed via a midline incision and cannulated with a sterile polypropylene 18-gauge catheter. The lungs were lavaged with $0.6 \mathrm{ml}$ of saline 2-times for an average of $1 \mathrm{ml}$ lavage fluid per lung. Lavage fluid was centrifuged $1500 \mathrm{~g}$ for 10 minutes at $4^{\circ} \mathrm{C}$ and supernatant was collected for protein assay. Lung tissue was subsequently harvested for digestion, assessment of cytokine levels, neutrophil influx, and apoptosis. In some 
experiments, spleens were harvested and gently ground to produce a single-cell suspension between frosted microscope slides. ${ }^{16}$ After hypotonic lysis of erythrocytes, splenocytes were washed once with PBS and cell numbers were counted and cell viability was assessed by Trypan Blue dye exclusion.

\section{Lung Histology}

The left lobe of the lung was harvested and either fixed in $10 \%$ formalin, paraffin embedded, stained with hematoxylin \& eosin before examination by light microscopy for lung morphology, ${ }^{10-11,13}$ or in some cases quick-frozen and acetone-fixed lung tissue sections were prepared for immunohisto-chemical analysis. For the frozen sections, after rinsing to remove mounting media, slides were incubated with purified rat anti-mPDCA-1 monoclonal antibody for one hour at room temperature in a humidified chamber. Slides were rinsed and incubated with a biotinylated mouse anti-rat $\operatorname{lgG}_{2 \mathrm{~b}}$ (BD biosciences, San Jose, CA) for 30 minutes at room temperature and then rinsed. Incubation with streptavidin-horseradish peroxidase was then performed for 30 minutes at room temperature, followed, after rinsing, by incubation with diaminobenzidine substrate for five minutes. Finally, slides were counterstained with methyl green for one minute and then analyzed by light microscopy. A process of specimen blinding was routinely used to mitigate the subjectivity of investigators determination of tissue morphology.

\section{Lung Myeloperoxidase Activity and Caspase 3 Activity Assay}

An assessment of lung myeloperoxidase activity, a marker for neutrophil influx, was measured according to established protocols. ${ }^{17}$ Lung tissue was homogenized in lysis buffer and protein concentration was assessed using the Bradford dye binding procedure (Bio-Rad, Hercules, CA). Caspase-3 activity in lung tissue was quantified by fluorometric analysis as described elsewhere. ${ }^{18}$

\section{Quantification of Cytokines/Chemokines}

Mouse MCP-1, tumor necrosis factor- $\alpha$ (TNF- $\alpha$ ), interleukin-6 (IL-6, BD biosciences), and interferon- $\alpha$ (IFN- $\alpha, \mathrm{PBL}$ Biomedical Laboratories, Piscataway, NJ) were measured on lung-tissue homogenate and plasma using commercially available sandwich ELISA kits. ${ }^{10-11,13}$

\section{Enzymatic Lung Digest}

Lung parenchymal cells were isolated from PBS-perfused whole lungs using a modification of methods described by Summer et al ${ }^{19}$ and De Paepe et al. ${ }^{20}$ In brief, after euthanization, the pleural and peritoneal cavities were opened via a midline incision. Clamps were placed on the superior vena cava and inferior vena cava, and lungs were flushed with cold Hanks' Balanced Salt solution (HBSS, GIBCO, Carlsbad, CA) infused through the right ventricle and drained through an incision made in the left ventricle. The whole lung (from which the large conducting airways were dissected away) was placed in a plastic culture dish in $2 \mathrm{ml}$ enzyme solution $(2.4 \mathrm{U} / \mathrm{ml}$ Dispase II, 0.1\% Collagenase A [Roche Applied Science, Indianapolis, IN], $2.5 \mathrm{mmol} / \mathrm{L} \mathrm{CaCl}_{2}$ [Sigma-Aldrich, St. Louis, MO] in HBSS). Lungs were then minced, transferred into a $50-\mathrm{ml}$ conical tube, and incubated at $37^{\circ} \mathrm{C}$ water bath for 45 minutes. One $\mathrm{ml}$ of cold HBSS was added to lung digest and the digest solution was pipetted up and down to break up remaining tissue. Lung digest solution was then passed through a 40- $\mu \mathrm{m}$ filter into a clean 50-ml conical tube and was centrifuged for 10 minutes, $500 \mathrm{~g}$ at $4^{\circ} \mathrm{C}$. The cellular pellet was washed with HBSS, resuspended in $1 \mathrm{ml}$ of HBSS, and total viable cell number was determined using Trypan Blue dye exclusion. Isolated cells were then phenotyped by flow cytometry.

\section{Flow Cytometry Phenotyping and Cell Sorting}

Relative percentages of dendritic cells, pDCs and mDCs, and monocytes/macrophages among total lung cells were measured by flow cytometry (BD FACSArray or BD FACSAria, San Diego, CA). Monoclonal antibodies and their respective isotype controls were used to stain lung cells according to manufacturer's recommendation: phycoerythrin (PE) or allophycocyanin (APC)-labeled anti-CD45, PE-labeled anti-CD115, APC-labeled antiCD80, PE, APC, or PECy7-labeled anti-CD11C, PE or APC-labeled anti-CD11b, PE or PECy7-labeled anti-B220, PE or APC-labeled anti-GR1, APC-labeled anti-MHC class II (eBioscience, San Diego, CA), APC-labeled anti-mPDCA-1, PE-labeled anti-Ly-6C (Miltenyi Biotec). CX3CR1 cell-surface staining was performed using a primary incubation with rabbit anti-CX3CR1 polyclonal IgG (eBioscience) followed by a secondary incubation using APC-labeled goat anti-rabbit antibody (R\&D Systems). Finally, cell sorting (BD FACSAria, San Diego, CA) was performed for the isolation of $\mathrm{pDCs}\left(\mathrm{CD} 11 \mathrm{c}^{+} \mathrm{GR} 1^{+} \mathrm{B} 22 \mathrm{O}^{+} \mathrm{PDCA}-1^{+}\right)$from lungs harvested from C57BL/6 mice after Hem + CLP.

\section{Cell Culture Experiments}

J774A. 1 cells (ATCC T1B-67 - murine monocyte/macrophage cell type) were cultured with isolated pDCs (1/10 ratio) and recombinant murine TNF- $\alpha$ ( $5 \mathrm{ng} / \mathrm{ml})$ in DMEM supplemented medium. Supernatants were harvested 24 hours later, and MCP-1 concentration was measured as described above.

\section{Statistical Analysis}

Data are presented as mean \pm SEM For multiple group comparison, and one-way analysis of variance was used followed by Student-Newman-Keuls method. ${ }^{21}$ For twogroup comparison, Mann-Whitney $U$ test was applied. $P<0.05$ was considered significant. 


\section{Results}

\section{Murine Model of Indirect Acute Lung Injury}

This model of indirect ALI induced in mice after Hem + CLP has been repeatedly used and described by our laboratory. ${ }^{10-13}$ Because we observed in preliminary experiments that the severity of indirect ALI was markedly increased in DC-depleted mice (increased number of deaths after Hem + CLP, increased weight loss, decreased physical activity, and food intake in comparison with C57BL/6 mice) for this set of experiments, the model was titered down not to induce too severe a lung injury in the background control (C57BL/6) mice. For this reason, only a small increase in BALF protein concentration and in proinflammatory cytokine production in C57BL/6 mice after Hem + CLP was routinely seen when compared with mice after CLP alone. To note, typical values measured in our lab in C57BL/6 mice after Hem + CLP are on average $0.4 \mathrm{mg} / \mathrm{ml}$ for BALF protein, $1000 \mathrm{pg} / \mathrm{ml}$ for plasmatic $\mathrm{IL}-6$, and $300 \mathrm{pg} / \mathrm{ml}$ for plasmatic MCP-1 concentrations. $^{22}$ Moreover, although we show only the sham Hem + CLP (which we have not found to differ from Hem + sham CLP) or sham Hem + sham CLP groups as our controls for the studies here, we have previously documented that neither Hem nor CLP alone is capable of inducing substantial/consistent increases in indices of lung inflammation, apoptosis, or injury in our model. ${ }^{10-12}$ Finally, as recommended by the Jackson laboratory, C57BL/6 mice were chosen as control (ie, mice without DC depletion after DTx injection) for CD11C-DTR mice. Both strains were thus equally treated with DTx throughout the study. Nevertheless, we verified in a preliminary experiment that (1) the percentage and number of lung DCs (Figure 1, A and B), (2) BALF protein concentration (data not shown), (3) lung myeloperoxidase activity (see Supplemental Figure 1B at http://ajp.amjpathol.org), (4) lung caspase 3 activity (see Supplemental Figure 1C at http://ajp.amjpathol.org), and (5) lung and plasma cytokine concentrations (data not shown) were not different in CD11C-DTR mice not depleted of DCs (ie, not treated with DTX) in comparison with C57BL/6 mice after Hem + CLP. Finally, the specificity for DC depletion of DTx treatment in CD11c-DTR mice was also verified. Beside the results presented in this article regarding BALF macrophages and lung neutrophils, we demonstrated in another set of experiments that lung $T$ cell number was similarly increased after Hem + CLP in these mice and in C57BL/6 mice treated with DTX. ${ }^{13}$

\section{The Number of Mature Dendritic Cells Is Increased in the Lung after Hem + CLP}

The role of DCs in the pathophysiology of indirect ALI has not been emphasized. To investigate this, CD11C-DTR mice, which have been engineered to express the human receptor for DTx linked with the CD11c molecule, ${ }^{23}$ and control C57BL/6 mice were injected i.p. with DTx 12 hours before the induction of indirect ALI by Hem followed 24 hours later by a polymicrobial septic challenge
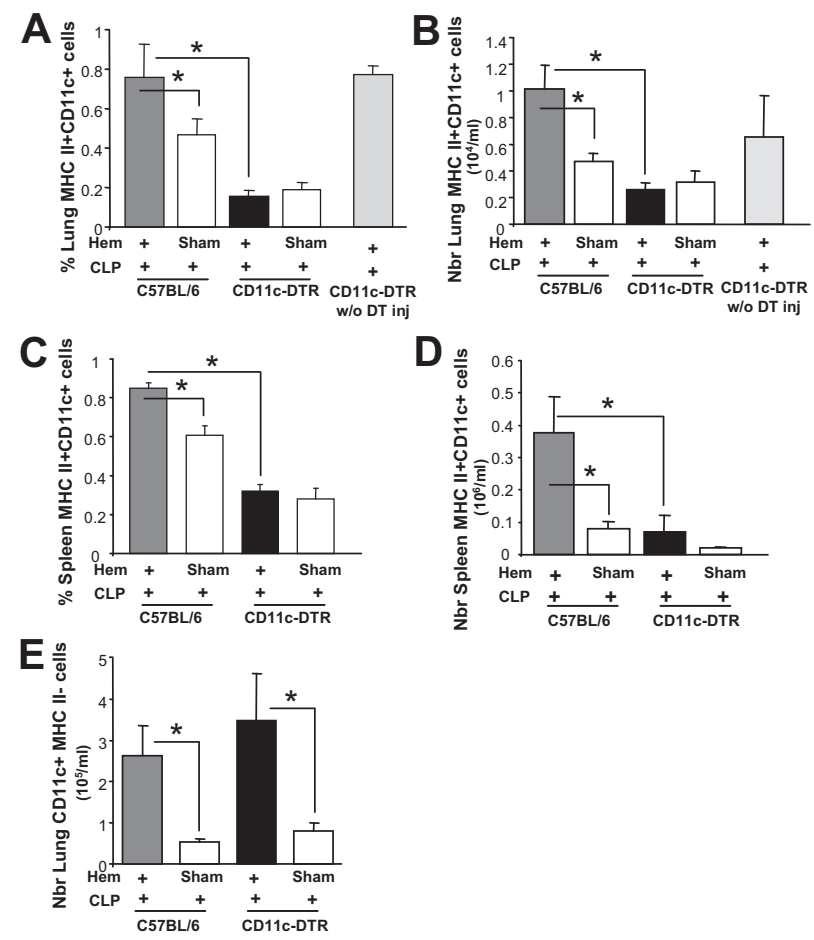

Figure 1. The number of mature dendritic cells is increased in the lung after Hem + CLP. CD11c-DTR (black bars) and C57BL/6 mice (dark gray bars) were injected intraperitoneally with diphtheria toxin $(4 \mu \mathrm{g} / \mathrm{kg}) 12$ hours before hemorrhagic shock (Hem) followed 24 hours later by cecal ligation and puncture (CLP, $n=10$ mice per group). As controls, mice were submitted to Sham Hem + CLP (white bars). CD11c-DTR mice $(n=3$, light gray bars) not treated with the toxin were also submitted to Hem + CLP. A Percentage of mature lung dendritic cells $\left(\mathrm{CD} 11 \mathrm{c}^{+} \mathrm{MHC} \mathrm{II}{ }^{+}\right) .{ }^{14} \mathbf{B}$ : Absolute number (Nbr) of mature lung dendritic cells. C: Percentage of mature splenic dendritic cells. D: Absolute number of mature splenic dendritic cells. E: Absolute number of resident lung macrophages (CD11 $\left.{ }^{+} \mathrm{MHC} \mathrm{II}^{-}\right) .{ }^{24}$ Values are expressed as mean \pm SEM. ${ }^{*} P<0.05$.

(CLP). The number of mature DCs was then measured by flow cytometry 24 hours after CLP in enzymatically-digested lungs (from which the large conducting airways were dissected away) and in the spleens. We initially observed that, in C57BL/6 mice as well as in CD11C-DTR mice not treated by DTx, both percentages (Figure 1A) and absolute count (Figure 1B) of lung CD11 ${ }^{+} \mathrm{MHC} \mathrm{I}{ }^{+}$ cells were increased after Hem + CLP in comparison with mice after CLP only. Interestingly, in the spleen as well, a similar increase was observed (Figure 1, C and D). In contrast, in DTx-treated CD11C-DTR mice, both percentage and absolute count of $\mathrm{CD} 11 \mathrm{C}^{+} \mathrm{MHC} \mathrm{II}^{+}$cells were found to be significantly decreased in comparison with C57BL/6 mice in lung (Figure 1, A and B) and spleen (Figure 1, C and D) after Hem + CLP. Of note, no decrease in the number of resident pulmonary macrophages $\left(\mathrm{CD} 11 \mathrm{C}^{+} \mathrm{MHC} \mathrm{II}^{-}\right.$lung cells ${ }^{24}$ ) was observed in CD11C-DTR mice in comparison with C57BL/6 after Hem + CLP (Figure 1E).

\section{Depletion of Lung Dendritic Cells Is Associated with an Increased Severity of Indirect ALI}

Markers of lung dysfunctions were monitored after Hem + CLP in CD11c-DTR and C57BL/6 mice injected 
A
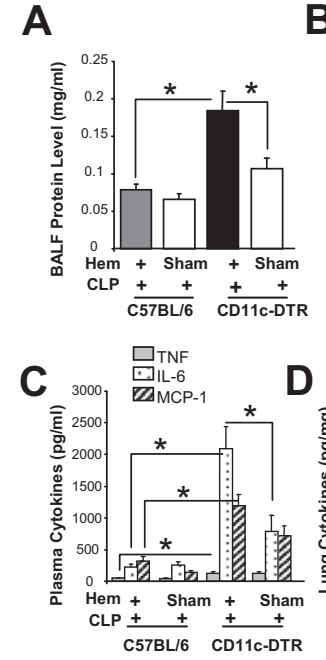

D
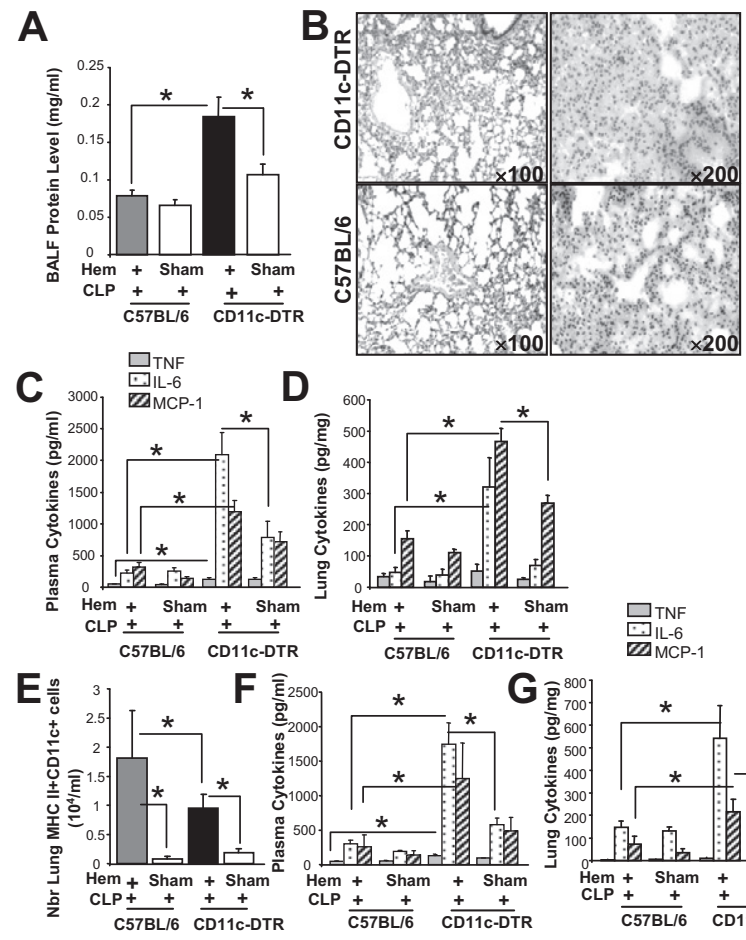

Figure 2. The severity of indirect acute lung injury is increased in DCdepleted mice. CD11c-DTR (black bars) and C57BL/6 mice (gray bars) were injected either intraperitoneally ( $4 \mu \mathrm{g} / \mathrm{kg}, n=10$ mice per group) (A-D) or intratracheally $(2 \mu \mathrm{g} / \mathrm{kg}, n=5$ mice per group; $\mathbf{E}-\mathbf{G})$ with diphtheria toxin 12 hours before hemorrhagic shock (Hem) followed 24 hours later by cecal ligation and puncture (CLP). As controls, mice were submitted to Sham Hem + CLP (white bars). A: Broncho-alveolar lavage fluids (BALF) protein concentration. B: Representative lung sections obtained after Hem + CLP and stained with hematoxylin and eosin. C: Plasma cytokine concentrations. D: Lung cytokine concentrations. E: Absolute number (Nbr) of mature lung dendritic cells $\left(\mathrm{CD} 11 \mathrm{c}^{+} \mathrm{MHC} \mathrm{II}{ }^{+}\right) .{ }^{14} \mathbf{F}$ : Plasma cytokine concentrations. G: Lung cytokine concentrations. Values are expressed as mean \pm SEM. ${ }^{*} P<0.05$.

i.p. with DTx. DC depletion led to increased BALF protein concentration after Hem + CLP (an index of lung permeability, Figure 2A) and increased alveolar septal thickening, associated with marked cellular infiltrates and alveolar congestion/collapse as observed in lung histology slides (histological indices of cell swelling and granulocyte influx, Figure 2B), suggesting that the severity of indirect ALI was increased in the absence of DCs. Increased neutrophil recruitment, apoptosis, and proinflammatory response play a fundamental role in the pathophysiology and the severity of indirect ALI. ${ }^{1} \mathrm{Al}-$ though we did not observe any change in lung neutrophil recruitment (measured both by the number of lung GR $1^{+}$ cells [see Supplemental Figure 1A at http://ajp.amjpathol. org] and lung myeloperoxidase activity [see Supplemental Figure $1 \mathrm{~B}$ at http://ajp.amjpathol.org]) or in lung caspase 3 activity (a marker of apoptosis [see Supplemental Figure 1C at http://ajp.amjpathol.org]) in DC-depleted mice in comparison with C57/BL6 mice, TNF- $\alpha$, IL-6, and MCP-1 concentrations were markedly increased both in the lung and plasma of DTx-treated CD11c-DTR mice after Hem + CLP in comparison with C57BL/6 mice (Figure 2, C and D). Immature DCs are present in the lung of naive mice and can be induced to mature after stimulation. Mature DCs can also be re- cruited from the periphery during infection/inflammation. ${ }^{7}$ We thus investigated whether the increased proinflammatory response seen in DC-depleted mice after Hem + CLP was attributable to the effect of locally activated or recruited DCs. To this end, local depletion of lung DCs was achieved by i.t. instillation of DTx before the induction of indirect ALI in CD11c-DTR and C57BL/6 mice by Hem + CLP. Lung instillation of DTx was associated with a significant reduction in the percentage (see Supplemental Figure 2A at http://ajp.amjpathol.org) and absolute count (Figure 2E) of CD11 $\mathrm{C}^{+} \mathrm{MHC} \mathrm{I}^{+}$cells in CD11CDTR mice compared with C57BL/6 mice. No such decrease was observed in the spleen (see Supplemental Figure 2, B and C at http://ajp.amjpathol.org). Most importantly, as observed in our first set of experiments, local depletion of lung DCs after Hem + CLP was associated with a major increase in pro-inflammatory cytokine response both in the plasma (Figure 2F) and the lung (Figure 2G). This suggests that DCs that are induced to mature locally in the lung after Hem + CLP play a protective anti-inflammatory role during indirect ALI in mice.

\section{Dendritic Cell Depletion Is Associated with the Recruitment of Proinflammatory Monocytes to the Lung after Hem + CLP}

Prior studies in our lab suggest that either pulmonary macrophages or epithelial cells have the capacity to produce proinflammatory cytokines/chemokines in response to shock and/or subsequent septic insult. ${ }^{22,25} \mathrm{~A}$ marked increase in the percentage and number of lung $\mathrm{CD}_{115^{+}}$cells was observed in DC-depleted mice after $\mathrm{Hem}+\mathrm{CLP}$ in comparison with C57BL/6 mice (Figure 3A). These cells expressed CD80 and CX3CR1 implying an activated/proinflammatory phenotype (Figure 3B), ${ }^{26}$ as well as CD11b but not CD11c further suggesting that they were monocytes newly recruited to the lung (Figure 3B). ${ }^{27}$ However, no GR1 expression could be detected on these cells (data not shown). Most importantly, depletion of lung $\mathrm{CD} 115^{+}$cells by liposomal clodronate i.t. instillation in DC-depleted mice was able to block the increased proinflammatory cytokine production seen in these mice, whereas instillation of control (PBS) liposomes had no such effect (Figure 3C). This suggests that the newly recruited $\mathrm{CD}_{115^{+}}$monocytes were playing a role in the increased proinflammatory cytokine production observed in DC-depleted mice after Hem + CLP. Finally, as the role of MCP-1 in the recruitment of monocytes to the lung during ALI has been previously described, ${ }^{28,29}$ and as we observed an increased lung MCP-1 concentration in association with an increased recruitment of proinflammatory monocytes in DC-depleted mice, we investigated the involvement of this chemokine on the recruitment of monocytes in our model. We observed that the specific blockage of lung MCP-1 activity using anti-MCP-1 Abs administered i.t. in CD11cDTR mice treated with DTx was associated with a decreased recruitment of $\mathrm{CD} 115^{+}$monocytes to a level that was not different from C57BL/6 mice after Hem + CLP 
A
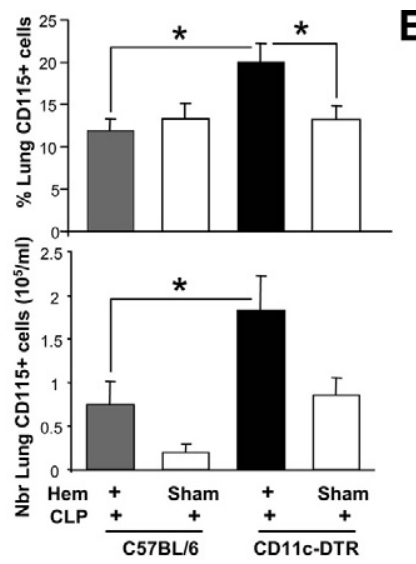

C
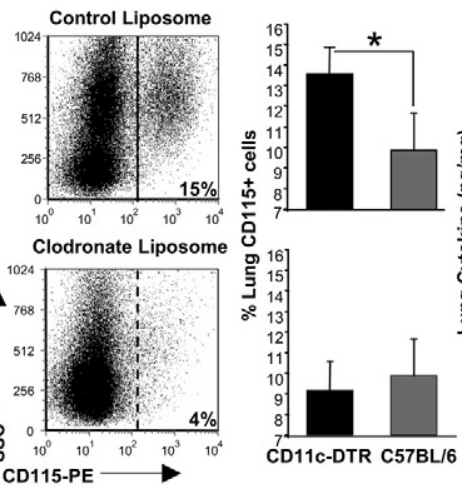

B
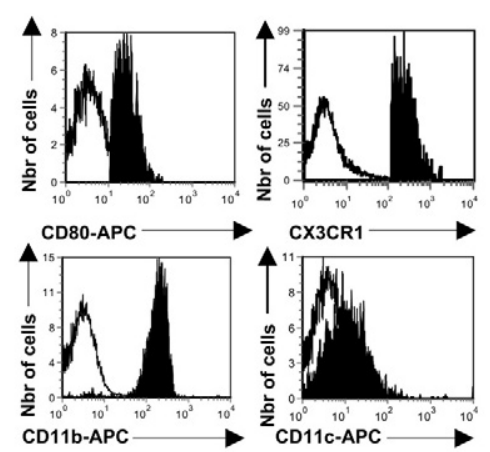

TNF

$\because \because \mathrm{IL}-6$

UMCP-1

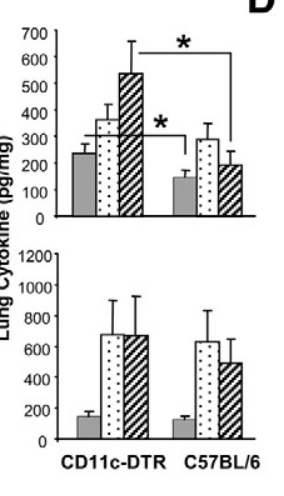

D

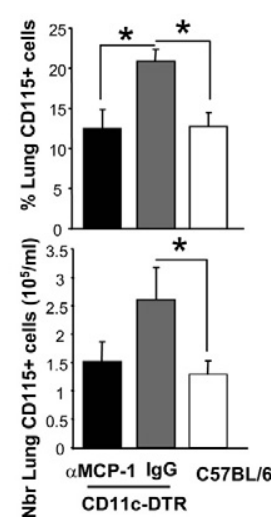

Figure 3. DC-depletion is associated with an increased recruitment of proinflammatory monocytes to the lung after Hem + CLP. CD11c-DTR (black bars) and C57BL/6 mice (gray bars) were injected intraperitoneally with diphtheria toxin $(4 \mu \mathrm{g} / \mathrm{kg}) 12$ hours before hemorrhagic shock (Hem) followed 24 hours later by cecal ligation and puncture (CLP, $n=8$ mice per group). As controls, mice were submitted to Sham Hem + CLP (white bars). A: Percentage and absolute number ( $\mathrm{Nbr}$ ) of recruited lung $\mathrm{CD}_{115^{+}}$cells. B: Representative histograms for cell-surface expressions of CD80, CX3CR1, CD11b, and CD11c molecules on lung CD $115^{+}$cells in CD11c-DTR mice after Hem + CLP (white histogram = isotype control). C: Clodronate and control (PBS) liposomes (100 $\mu \mathrm{l} /$ mouse) were administered intratracheally in CD11cDTR and C57BL/6 mice treated with diphtheria toxin 12 hours before Hem + CLP. Percentage of lung CD115 ${ }^{+}$ cells and lung cytokine concentrations were measured. D: Anti-MCP-1 blocking antibodies $(\alpha$ MCP-1 Abs black bars) or $\operatorname{IgG}(75 \mu \mathrm{g} /$ mouse - gray bars $)$ were administered intratracheally 12 hours before Hem + CLP in CD11c-DTR mice treated with diphtheria toxin $(n=4$ to 6 mice per group). Percentage and absolute count of lung $\mathrm{CD} 115^{+}$cells were measured. Values are expressed as mean \pm SEM. ${ }^{*} P<0.05$.
(Figure 3D). This suggests that lung DCs control the recruitment of proinflammatory monocytes during indirect $A L I$ in mice through the regulation of lung MCP-1 production.

\section{Both Myeloid and Plasmacytoid Dendritic Cells Are Induced in the Lung after Hem + CLP}

Both $\mathrm{mDCs}$ and $\mathrm{pDC}$ are present in the lung of normal mice. $^{7}$ We observed that the number of both mDCs
$\left(\mathrm{CD} 11 \mathrm{c}^{+} \mathrm{MHC} \mathrm{II}^{+} \mathrm{CD} 11 \mathrm{~b}^{+}\right.$- Figure $\left.4 \mathrm{~A}\right)$ and pDCs $\left(\mathrm{CD} 11 \mathrm{C}^{+} \mathrm{GR} 1^{+} \mathrm{B} 22 \mathrm{O}^{+} \mathrm{PDCA}-1^{+}\right.$- Figure $\left.4 \mathrm{~B}\right)$ were markedly increased in the lung of C57BL/6 mice after Hem + CLP in comparison with mice after CLP alone or naïve mice. Most importantly, we verified that these two DC subpopulations were depleted after Hem + CLP in the lung of CD11C-DTR mice treated with DTx (Figure 4C). Regarding $\mathrm{pDCs}$, this was also confirmed by PDCA-1 immunohistological staining (Figure 4D). Finally, we observed that the increased number of pDCs after $\mathrm{Hem}+$
A
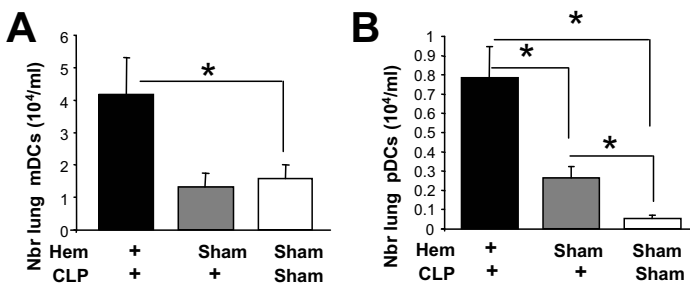

D

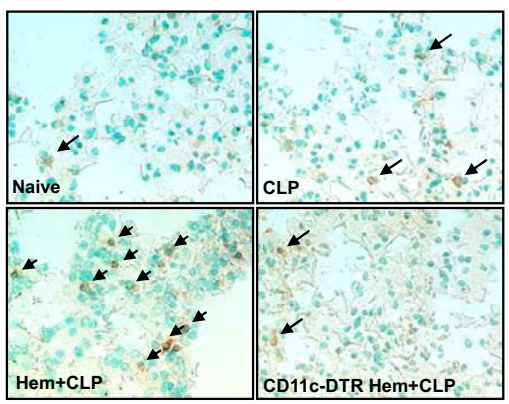

C

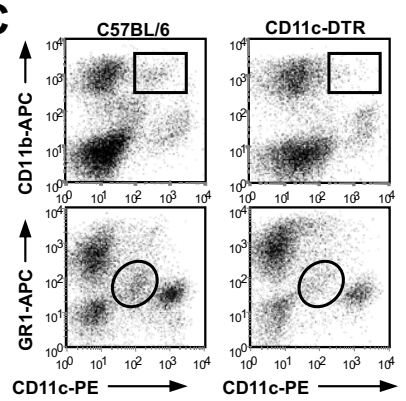

E

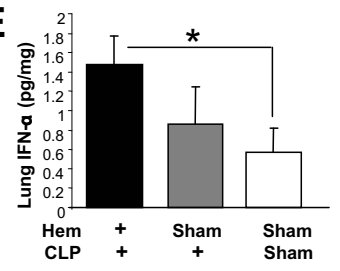

Figure 4. Both $\mathrm{mDCs}$ and $\mathrm{pDCs}$ are induced in the lung after Hem + CLP and are depleted in CD11c-DTR mice injected with diphtheria toxin. C57BL/6 mice were submitted to hemorrhagic shock (Hem) followed 24 hours later by cecal ligation and puncture (CLP - black bars). As controls, mice were submitted to Sham Hem + CLP (gray bars). Results in naive mice are also presented (white bars). A: Absolute number (Nbr) of lung $\mathrm{mDCs}$ $\left(\mathrm{CD} 11 \mathrm{c}^{+} \mathrm{MHC} \mathrm{II}^{+} \mathrm{CD} 11 \mathrm{~b}^{+}\right)$. B: Absolute number of lung $\mathrm{pDCs}\left(\mathrm{CD} 11 \mathrm{c}^{+} \mathrm{GR} 1^{+} \mathrm{B} 220^{+} \mathrm{PDCA}-1^{+}\right)$. C CD11c-DTR and C57BL/6 mice were injected intraperitoneally with diphtheria toxin $(4 \mu \mathrm{g} / \mathrm{kg}) 12$ hours before Hem + CLP. One representative dot-plot is shown for both mDCs $\left(\mathrm{CD} 11 \mathrm{~b}^{+} \mathrm{CD} 11 \mathrm{c}^{+}\right)$and pDCs $\left(\mathrm{GR} 1^{+} \mathrm{CD} 11 \mathrm{c}^{+}\right)$stainings in $\mathrm{C} 57 \mathrm{BL} / 6$ and CD11c-DTR mice. D: Representative slides for frozen lung sections immunohistochemically stained with anti-mPDCA-1 antibody. Black arrows show positive staining. E: Lung IFN- $\alpha$ concentration measured in $\mathrm{C} 57 \mathrm{BL} / 6$ mice. Values are expressed as mean $\pm \operatorname{SEM}(n=5$ to 8 mice per group). ${ }^{*} P<0.05$. 
A
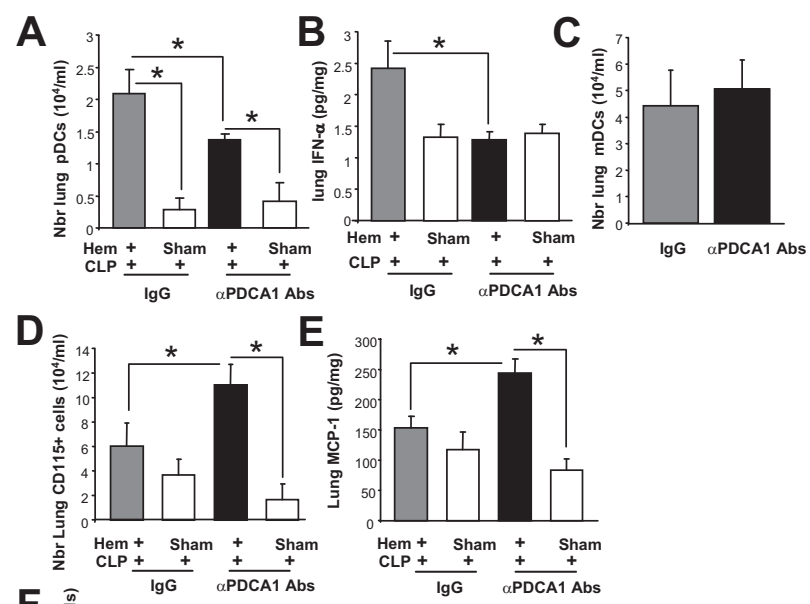

$\mathbf{F}$

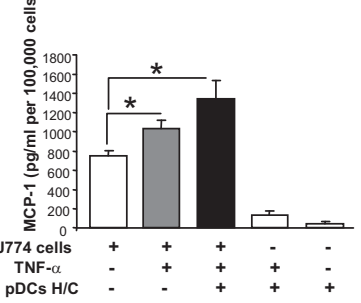

Figure 5. Lung pDC-depletion is associated with an increased recruitment of proinflammatory monocytes to the lung after Hem + CLP. C57BL/6 mice were injected intratracheally with anti-PDCA-1 antibodies ( $\alpha$ PDCA1 Abs black bars) or IgG (100 $\mu \mathrm{g} /$ mouse-gray bars) 12 hours before hemorrhagic shock (Hem) followed 24 hours later by cecal ligation and puncture (CLP, $n=5$ mice per group). As controls, mice were submitted to Sham Hem + CLP (white bars). A: Absolute number (Nbr) of lung pDCs $\left(\mathrm{CD} 11 \mathrm{c}^{+} \mathrm{GR} 1^{+}\right.$ B220 ${ }^{+}$PDCA $\left.-1^{+}\right)$. B: Lung IFN- $\alpha$ concentration. C: Absolute number of lung mDCs $\left(\mathrm{CD} 11 \mathrm{c}^{+} \mathrm{MHC} \mathrm{II}^{+} \mathrm{CD} 11 \mathrm{~b}^{+}\right)$. D: Absolute number of lung $\mathrm{CD} 115^{+}$ cells. E: Lung MCP-1 concentration. F: MCP-1 concentration in the supernatant of cell-sorted lung pDCs incubated 24 hours with J774 monocytes (1/10 ratio) in the presence of recombinant murine TNF- $\alpha(5 \mathrm{ng} / \mathrm{ml})$. Values are expressed as mean \pm SEM. ${ }^{*} P<0.05$.

CLP was associated with an increased lung IFN- $\alpha$ production (Figure 4E), suggesting that these cells were activated in the lung during this process.

\section{Lung Plasmacytoid DC-Depletion Reproduces the Effects Observed in DC-Depleted Mice after Hem + CLP}

Previous studies have shown that lung pDCs can play an immunoregulatory role after infection, which may be crucial for the prevention of excessive immune activation and immunopathology. ${ }^{30,31}$ Here we observed that i.t. instillation of anti-PDCA-1 antibodies (Abs) 12 hours before the induction of indirect ALI in C57BL/6 mice was associated with a significant reduction in lung $\mathrm{pDC}$ number (Figure 5A) and lung IFN- $\alpha$ production (Figure 5B) suggesting that a complete blockade of injury-induced lung pDC activation was achieved. In this model no decrease in lung $\mathrm{mDC}$ number was observed (Figure 5C). Most importantly, as observed earlier in CD11c-DTR mice, pDC-depletion led to an increased recruitment of $\mathrm{CD}_{115^{+}}$monocytes to the lung (Figure 5D) that was associated with an increased lung MCP-1 production (Figure 5E) after Hem + CLP. Therefore, among the DC subpopulations that are present in the lung, pDCs might play a protective anti-inflammatory role during indirect ALI through the regulation of the recruitment of proinflammatory monocytes. Finally, because among other cell populations $\mathrm{CD}_{115^{+}}$monocytes themselves can produce increased MCP-1 after stimulation, we investigated whether lung pDCs could regulate this production via a direct interaction with monocytes. To this end, lung pDCs were cell sorted after Hem + CLP and cultured 24 hours with $\mathrm{J} 774$ monocyte cells stimulated with recombinant TNF- $\alpha$. However, in vitro, no regulatory effect of lung pDCs on the increased production of MCP-1 by J774 monocytes after stimulation with TNF- $\alpha$ was observed (Figure 5F). This suggests that the regulation by pDCs of MCP-1 production and monocyte recruitment to the lung during indirect ALI is not attributable to a direct effect (neither via cell-cell interaction nor through the release of a soluble factor) of pDCs on monocytes.

\section{Discussion}

The early development of indirect ALI is characterized by the recruitment to the lung of activated neutrophils and monocytes/macrophages, experiencing a delay in apoptosis and an increase in respiratory burst. ${ }^{1,5,32}$ Concomitantly, lung epithelial cells undergo apoptosis, ${ }^{33}$ thus contributing to destruction of the pulmonary epithelium and compromised barrier function. ${ }^{1,32}$ Here we describe the involvement of a novel cell population in the pathophysiology of indirect ALI: we showed that pDCs are induced and activated in the lung after Hem + CLP and play an inhibitory role in the recruitment of proinflammatory monocytes through the regulation of lung MCP-1 production.

In healthy lungs, immature DCs reside in airway epithelium, alveolar septae, and around pulmonary vessels. ${ }^{34}$ In response to infection/inflammation, the number of mature DCs increases dramatically in the lung, in some cases peaking already at two hours after challenge. ${ }^{7,35}$ This increase in number can be attributable to the recruitment of mature DCs from the blood stream or the local maturation of resident lung DCs. ${ }^{7}$ In our model, despite the absence of direct lung injury, an increase in the number of mature DCs $\left(\mathrm{CD} 11 \mathrm{C}^{+} \mathrm{MHC} \mathrm{I}^{+}\right)$in the lung was observed after Hem + CLP. Most interestingly, this increase was mainly attributable to local maturation of DCs despite a small recruitment from the periphery.

Two DC phenotypes are important for lung defenses: mDCs, which are by far the predominating lung DC population (>95\%) and the newly described pDCs. ${ }^{30}$ We observed that both pDCs and mDCs numbers were increased in the lung after Hem + CLP and that pDCs were activated during this process since lung IFN- $\alpha$ production was increased after Hem + CLP.

DCs have been shown to be activated by LPS, mycopeptides, and viral RNA because of their expression of toll-like receptors, and by dying cells or cells from the adaptive or innate immune system. ${ }^{36}$ Most interestingly, it has been described that the maturation stage of lung DCs profoundly governs a state of tolerance or immunity in the lung. ${ }^{35}$ In line, our data suggest that pDCs are 
"primed" to mature and are activated [even though factor(s) (soluble or cell-mediated) responsible for their maturation in this model remain to be determined] and play an anti-inflammatory role in the lung during indirect ALI. Therefore, the concept of "priming" that has been shown to occur at several cellular levels during indirect ALI and to play significant roles in mediating the increased inflammation associated with this injury, ${ }^{1,6}$ might be playing a role in the activation of anti-inflammatory mechanisms in the lung during indirect ALI as well.

So far, no data are available regarding the role of lung DCs in the pathophysiology of indirect ALI. We first observed that DC depletion was associated with an increased severity of lung injury. Similarly, after CLP alone, Scumpia et al observed that DC depletion was associated with an increased mortality in mice. ${ }^{14}$ In our model, this was not attributable to increased apoptosis or increased neutrophil recruitment to the lung but rather appears to be attributable to the recruitment of a population of proinflammatory $\mathrm{CD} 115^{+}$monocytes.

Moreover, selective pDC depletion was able to reproduce the effects observed in DC-depleted mice, implying that pDCs that are induced/activated in the lung during indirect ALI play an inhibitory role in the recruitment of pro-inflammatory monocytes to the lung.

PDCs in the lung are immature, expressing low levels of $\mathrm{MHC}$ II and costimulatory molecules yet high levels of the inhibitory B7 family member PD-L1 known to suppress $\mathrm{T}$ cell activation through interaction with $\mathrm{PD}-1 .{ }^{30}$ This profile of high inhibitory and low costimulatory molecule expression together with the poor T cell stimulatory capacity ex vivo point to the immunoregulatory role of pDCs in the lung and these cells have been shown to protect against the development of airway inflammation to harmless antigens. ${ }^{30}$

Moreover, recent studies have shown the capacity of subsets of DCs to directly regulate the innate immune response. Very similarly to our results, Abe et al showed in a murine model of colitis that, depending on their mode of activation, DCs could regulate colonic inflammation by inhibiting macrophages proinflammatory cytokine production. ${ }^{37}$ Moreover, Fujita et al observed a crucial role for tolerogenic DCs not only in regulating T-cell responses in acquired immunity but also in the damping of host local and systemic inflammatory responses to microbial pathogens in innate immunity. ${ }^{38}$ Their data showed that DCs were able to suppress the production of proinflammatory cytokines by inflammatory macrophages. Importantly, Kool et al recently demonstrated that lung pDCs were recruited to the lung in a model of allergic asthma and regulated airway inflammation because their removal using specific pDC-depleting Abs enhanced inflammation. ${ }^{39}$ These data, along with ours, expand the role of DCs beyond T cell activation and position pDCs as important inhibitors of acute inflammation.

Monocytes are central players in the pathophysiology of ALI/ARDS. ${ }^{1,5}$ An early expansion of mononuclear phagocyte population has been observed in the BALF of patients with ARDS, which was mainly attributable to a rapid influx of monocytes from the vascular compartment. ${ }^{29}$ Similarly, we observed a marked increase in the number of BALF macrophages both in control and in DC-depleted mice after Hem + CLP (Figure 1E). Most importantly, in patients, continuous recruitment of monocytes to the lung was associated with increased mortality, whereas patients presenting with decreased monocyte influx and normalization of the mononuclear phagocyte population concentration had a better survival. ${ }^{29}$ This suggests that the continuous recruitment of monocytes to the lung in ARDS plays a deleterious role in the pathophysiology of ALI/ARDS, and that ways to decrease/ block this recruitment might represent new avenues in treating this disease. ${ }^{29}$

Upregulation and secretion of MCP-1 in the alveolar compartment appears to be central to this process with strong correlation with the severity of respiratory failure. Elevated MCP-1 levels in BALF have been demonstrated in patients with ARDS. ${ }^{40}$

MCP-1 expression in monocytes is induced by transendothelial migration and interaction with extracellular matrix protein, ${ }^{41,42}$ suggesting that monocytes themselves trigger sustained monocyte recruitment and promote ongoing inflammation in ALI, in accordance with our data. Interestingly, we observed that pDCs were playing a role in this process because MCP- 1 concentration was markedly increased in pDC-depleted mice in association with increased monocyte recruitment. Moreover, in DCdepleted mice, MCP-1 blockade was associated with a decreased $\mathrm{CD} 115^{+}$cell recruitment after Hem + CLP. However, in our model, this was not attributable to a direct interaction between pDCs and monocytes.

One can argue that monocytes and macrophages may not be the only cells responsible for MCP- 1 secretion in ALI. Indeed, epithelial cells (EpCs) have been shown to secrete MCP- 1 constitutively and in response to TNF- $\alpha$ and IL-1, ${ }^{43,44}$ and they showed a polar secretion of this chemokine into the apical compartment for initiating or maintaining a chemotactic gradient. ${ }^{45}$ DCs have been found to exist within the epithelium of the lung ${ }^{43}$ Such a close neighborhood per se strongly suggests an extensive DCs-EpCs cooperation. Moreover, during inflammation, EpCs are one of the principal sources of the chemokines, including MCP-1, necessary to attract immature DCs and monocytes. ${ }^{43,44}$ Lung EpCs therefore appear, in our model, as a potential central third player in the regulation of the recruitment of proinflammatory monocytes by lung pDCs. This deserves to be investigated in additional experiments.

In conclusion, our work shows that pDCs are induced and activated in the lung during indirect ALI in mice and control the recruitment of proinflammatory monocytes through the regulation of lung MCP-1 production. As our understanding of the pathophysiology of indirect ALI improves, new strategies will evolve to prevent and cure this deadly disease. Given that transplantation of DCs has provided a novel therapeutic approach to treat cancer and HIV patients ${ }^{36}$ and has shown positive effect on treating lung dysfunctions in murine models of sepsis, ${ }^{46,47}$ transplantation of immunocompetent DCs/pDCs might represent a potential therapeutic strategy to treat patients with indirect ALI. 


\section{Acknowledgments}

We thank Mr. Paul Monfils (Core Research Laboratories) for assistance with histology and Ms. Stephanie Terrizzi (Brown University Flow Cytometry Facility) for assistance with flow cytometry and cell sorting on BD FACSAria.

\section{References}

1. Ware LB, Matthay MA: The acute respiratory distress syndrome. N Engl J Med 2000, 342:1334-1339

2. Rubenfeld GD, Caldwell E, Peabody E, Weaver J, Martin DP, Neff M, Stern EJ, Hudson LD: Incidence and outcome of acute lung injury. N Engl J Med 2005, 353:1685-1693

3. Bersten AD, Edibam C, Hunt T, Moran J: Australian and New Zealand Intensive Care Society Clinical Trials Group. Incidence and mortality of acute lung injury and the acute respiratory distress syndrome in three Australian States. Am J Respir Crit Care Med 2002, 165:443-448

4. Sharma S, Kumar A: Septic shock, multiple organ failure, and acute respiratory distress syndrome. Curr Opin Pulm Med 2003, 9:199-209

5. Sevransky J, Martin GS, Mendez-Tellez P, Shanholtz C, Brower R, Pronovost PJ, Needham DM: Pulmonary versus non-pulmonary sepsis and mortality in acute lung injury. Chest 2008, 134:534-538

6. Perl M, Lomas-Neira J, Chung CS, Ayala A: Epithelial cell apoptosis and neutrophil recruitment in acute lung injury-a unifying hypothesis? What we have learned from small interfering RNAs Mol Med 2008, 14:465-475

7. Vermaelen K, Pauwels R: Pulmonary dendritic cells. Am J Respir Crit Care Med 2005, 172:530-551

8. de Heer HJ, Hammad H, Kool M, Lambrecht BN: Dendritic cell subsets and immune regulation in the lung. Semin Immunol 2005, 17:295-303

9. van Rijt LS, Jung S, Kleinjan A, Vos N, Willart M, Duez C, Hoogsteden $\mathrm{HC}$, Lambrecht BN: In vivo depletion of lung CD11c+ dendritic cells during allergen challenge abrogates the characteristic features of asthma. J Exp Med 2005, 201:981-991

10. Perl M, Chung CS, Lomas-Neira J, Rachel TM, Biffl WL, Cioffi WG, Ayala A: Silencing of Fas- but not caspase-8 in lung epithelial cells ameliorates pulmonary apoptosis, inflammation, and neutrophil influx after hemorrhagic shock and sepsis. Am J Pathol 2005, 167:1545-1559

11. Ayala A, Chung CS, Lomas JL, Song GY, Doughty LA, Gregory SH, Cioffi WG, LeBlanc BW, Reichner J, Simms HH, Grutkoski PS: Shock induced neutrophil mediated priming for acute lung injury in mice divergent effects of TLR-4 and TLR-4/FasL deficiency. Am J Pathol 2002, 161:2283-2294

12. Lomas-Neira J, Chung CS, Grutkoski PS, Miller EJ, Ayala A. CXCR2 inhibition suppresses hemorrhage-induced priming for acute lung injury in mice. J Leukoc Biol 2004, 76:1-7

13. Venet F, Chung CS, Huang X, Lomas-Neira J, Chen Y, Ayala A. Lymphocytes in the development of lung inflammation: a role for regulatory CD4+ T cells in indirect pulmonary lung injury. J Immunol 2009, 183:3472-3480

14. Scumpia PO, McAuliffe PF, O'Malley KA, Ungaro R, Uchida T, Matsumoto T, Remick DG, Clare-Salzler MJ, Moldawer LL, Efron PA: CD11c+ dendritic cells are required for survival in murine polymicrobial sepsis. J Immunol 2005, 175:3282-3286

15. Berg JT, Lee ST, Thepen T, Lee CY, Tsan MF: Depletion of alveolar macrophages by liposome-encapsulated dichloromethylene diphosphonate. J Appl Physiol 1993, 74:2812-2819

16. Ayala A, Deol ZK, Lehman DL, Herdon CD, Chaudry IH: Polymicrobial sepsis but not low dose endotoxin infusion causes decreased splenocyte IL-2/IFN-gamma release while increasing IL-4/IL-10 production. J Surg Res 1994, 56:579-585

17. Lukaszewicz GC, Souba WW, Abcouwer SF: Induction of cytokineinduced neutrophil chemoattractant (CINC) mRNA in the lungs of septic rats. J Trauma 1996, 41:222-230

18. Rodriguez I, Matsuura K, Ody C, Nagata S, Vassalli P: Systemic injection of a tripeptide inhibits the intracellular activation of
CPP32-like proteases in vivo and fully protects mice against Fasmediated fulminant liver destruction and death. J Exp Med 1996, 184:2067-2072

19. Summer R, Kotton DN, Sun X, Ma B, Fitzsimmons K: Side population cells and Bcrp1 expression in lung. Am J Physiol Lung Cell Mol Physiol 2003, 285:L97-L104

20. De Paepe ME, Mao Q, Embree-Ku M, Rubin LP, and Luks FI: Fas/ FasL-mediated apoptosis in perinatal murine lungs. Am J Physiol Lung Cell Mol Physiol 2004, 287:L730-L742

21. Sokal RR, Rohlf FJ: Biometry: the principles and practice of statistics in biological research. W.H. Freeman \& Co., San Francisco CA, 1969, pp 776

22. Perl M, Chung CS, Perl U, Lomas-Neira J, de Paepe M, Cioffi WG, Ayala A: Fas induced pulmonary apoptosis and inflammation during extrapulmonary acute lung injury. Am J Respir Crit Care Med 2007, 176:591-601

23. Bennett $\mathrm{CL}$, Clausen BE: DC ablation in mice: promises, pitfalls, and challenges. Trends Immunol 2007, 28:525-531

24. Vermaelen K, Pauwels R: Accurate and simple discrimination of mouse pulmonary dendritic cell and macrophage populations by flow cytometry: methodology and new insights. Cytometry A 2004, 61:170-177

25. Lomas-Neira J, Chung CS, Perl M, Gregory S, Biffl W, Ayala A: Role of alveolar macrophage and migrating neutrophils in hemorrhageinduced priming for ALI subsequent to septic challenge. Am J Physiol 2006, 290:L51-L58

26. Auffray C, Fogg D, Garfa M, Elain G, Join-Lambert O, Kayal S, Sarnacki S, Cumano A, Lauvau G, Geissmann F: Monitoring of blood vessels and tissues by a population of monocytes with patrolling behavior. Science 2007, 317:666-670

27. Li XC, Miyasaka M, Issekutz TB: Blood monocyte migration to acute lung inflammation involves both CD11/CD18 and very late activation antigen-4-dependent and independent pathways. J Immunol 1998, 161:6258-6264

28. Maus U, von Grote K, Kuziel WA, Mack M, Miller EJ, Cihak J, Stangassinger M, Maus R, Schlöndorff D, Seeger W, Lohmeyer J: The role of CC chemokine receptor 2 in alveolar monocyte and neutrophil immigration in intact mice. Am J Respir Crit Care Med 2002, 166:268-273

29. Rosseau S, Hammerl $P$, Maus U, Walmrath HD, Schütte $H$, Grimminger F, Seeger W, Lohmeyer J: Phenotypic characterization of alveolar monocyte recruitment in acute respiratory distress syndrome. Am J Physiol Lung Cell Mol Physiol 2000, 279:L25-L35

30. de Heer HJ, Hammad H, Soullié T, Hijdra D, Vos N, Willart MA, Hoogsteden HC, Lambrecht BN: Essential role of lung plasmacytoid dendritic cells in preventing asthmatic reactions to harmless inhaled antigen. J Exp Med 2004, 200:89-98

31. Smit JJ, Rudd BD, Lukacs NW: Plasmacytoid dendritic cells inhibit pulmonary immunopathology and promote clearance of respiratory syncytial virus. J Exp Med 2006, 203:1153-1159

32. Matute-Bello G, Liles WC, Radella F 2nd, Steinberg KP, Ruzinski JT, Hudson LD, Martin TR: Modulation of neutrophil apoptosis by granulocyte colony-stimulating factor and granulocyte/macrophage colony-stimulating factor during the course of acute respiratory distress syndrome. Crit Care Med 2000, 28:1-7

33. Kitamura Y, Hashimoto S, Mizuta N, Kobayashi A, Kooguchi K, Fujiwara I, Nakajima H: Fas/FasL-dependent apoptosis of alveolar cells after lipopolysaccharide-induced lung injury in mice. Am J Respir Crit Care Med 2001, 163:762-769

34. Holt PG, Stumbles PA: Regulation of immunologic homeostasis in peripheral tissues by dendritic cells: the respiratory tract as a paradigm. J Allergy Clin Immunol 2000, 105:421-429

35. Novak N, Bieber T: 2. Dendritic cells as regulators of immunity and tolerance. J Allergy Clin Immunol 2008, 121:S370-S374

36. Ueno H, Klechevsky E, Morita R, Aspord C, Cao T, Matsui T, Di Pucchio T, Connolly J, Fay JW, Pascual V, Palucka AK, Banchereau $\mathrm{J}$ : Dendritic cell subsets in health and disease. Immunol Rev 2007, 219:118-142

37. Abe K, Nguyen KP, Fine SD, Mo JH, Shen C, Shenouda S, Corr M, Jung S, Lee J, Eckmann L, Raz E: Conventional dendritic cells regulate the outcome of colonic inflammation independently of T cells. Proc Natl Acad Sci 2007, 104:17022-17027

38. Fujita S, Seino K, Sato K, Sato Y, Eizumi K, Yamashita N, Taniguchi M Sato K: Regulatory dendritic cells act as regulators of acute lethal systemic inflammatory response. Blood 2006, 107:3656-3664 
39. Kool M, van Nimwegen M, Willart MA, Muskens F, Boon L, Smit JJ, Coyle A, Clausen BE, Hoogsteden HC, Lambrecht BN, Hammad H: An anti-inflammatory role for plasmacytoid dendritic cells in allergic airway inflammation. J Immunol 2009, 15:1074-1082

40. Goodman RB, Strieter RM, Martin DP, Steinberg KP, Milberg JA, Maunder RJ, Kunkel SL, Walz A, Hudson LD, Martin TR: Inflammatory cytokines in patients with persistence of the acute respiratory distress syndrome. Am J Respir Crit Care Med 1996, 154:602-611

41. Takahashi M, Masuyama J, Ikeda U, Kasahara T, Kitagawa S, Takahashi Y, Shimada K, Kano S: Induction of monocyte chemoattractant protein-1 synthesis in human monocytes during transendothelial migration in vitro. Circ Res 1995, 76:750-757

42. Lukacs NW, Strieter RM, Elner V, Evanoff HL, Burdick MD, Kunkel SL: Production of chemokines, interleukin-8 and monocyte chemoattractant protein-1, during monocyte: endothelial cell interactions. Blood 1995, 86:2767-2773
43. Shaykhiev R, Bals R: Interactions between epithelial cells and leukocytes in immunity and tissue homeostasis. J Leukoc Biol 2007, 82:1-15

44. Standiford TJ, Kunkel SL, Phan SH, Rollins BJ, Strieter RM: Alveolar macrophage-derived cytokines induce monocyte chemoattractant protein-1 expression from human pulmonary type II-like epithelial cells. J Biol Chem 1991, 266:9912-9918

45. Paine R 3rd, Rolfe MW, Standiford TJ, Burdick MD, Rollins BJ, Strieter RM: MCP-1 expression by rat type II alveolar epithelial cells in primary culture. J Immunol 1993, 150:4561-4570

46. Benjamim CF, Lundy SK, Lukacs NW, Hogaboam CM, Kunkel SL: Reversal of long-term sepsis-induced immunosuppression by dendritic cells. Blood 2005, 105:3588-3595

47. Pène F, Zuber B, Courtine E, Rousseau C, Ouaaz F, Toubiana J, Tazi A, Mira JP, Chiche JD: Dendritic cells modulate lung response to Pseudomonas aeruginosa in a murine model of sepsis-induced immune dysfunction. J Immunol 2008, 181:8513-8520 